\title{
Macronutrient intake in overweight adults with chronic spinal cord injury - analysis before and after dietetic intervention
}

\author{
S. S. Wong ${ }^{1,2}$, L. Spillman ${ }^{1}$, A. Graham ${ }^{1}$, G. Grimble ${ }^{2}$ and A. Forbes ${ }^{2}$ \\ ${ }^{1}$ National Spinal Injuries Centre, Stoke Mandeville Hospital, Aylesbury and ${ }^{2}$ Centre of Gastroenterology and Clinical \\ Nutrition, University College London Hospital, Aylesbury Correspondence: Samford Wong, email address: \\ Samford.Wong@buckshosp.nhs.uk
}

Approximately 40,000 British people currently live with spinal cord injury (SCI) ${ }^{(1)}$ and up to $60 \%$ are estimated to be overweight or obese $^{(2)}$. This study aims (i) to describe the macronutrient intake in a sample of adults with SCI before they attend a weight management clinic with reference to the UK Reference Nutrient Intake, ${ }^{(3)}$ and (ii) to determine if there is any difference after dietetic interventions (analysis by paired $t$-test). Thirty-two chronic SCI adults $\left(52.4 \pm 11.5\right.$ years; body mass index $(\mathrm{BMI}): 32.9 \pm 4.7 \mathrm{~kg} / \mathrm{m}^{2} ; 41 \%$ female) macronutrient intake were analysed at baseline and follow-up by 7-day food diary (Table). Intake of the following macronutrients was reduced significantly after dietetic intervention: energy $(1,647 \mathrm{kcal} v .1,353 \mathrm{kcal}, p=0.029)$, total fat $(62.1 \mathrm{~g} v .48 .3 \mathrm{~g}, p=0.005)$, saturated fatty acids $(20.1 \mathrm{~g} v .15 .8 \mathrm{~g}, p=0.001)$ and alcohol $(6.87 \mathrm{~g} v .2 .86 \mathrm{~g}, p=0.003)$. Both males and females were however found to consume more sugar and protein than the RNI. There was a lower intake of dietary fibre than in the RNI. Energy intake appeared to be $15 \%$ less than the estimated needs (Henry's approach ${ }^{(4)} v$. 7-day food diary intake: $8.9 \mathrm{MJ} / \mathrm{d} v .7 .65 \mathrm{MJ} / \mathrm{d}, p<0.01$ ). The present study shows that simple dietetic intervention can improve the quality of the patient's diet, and there is some evidence that nutrient imbalance in SCI patients relative to the RNI can also be improved. Current guidance on nutritional requirement may be important overestimates for the SCI population. Despite energy intakes at lower than estimated needs the SCI population experiences damaging weight gain. To prevent obesity, we tentatively propose a reduction of $15 \%$ of total energy need provision from that proposed by standard predictive equations for individuals with SCI. In order to determine the optimal nutritional requirements in this specific high risk group of patients, further research, measuring energy expenditure and nutrient intake, is warranted.

\begin{tabular}{|c|c|c|c|c|c|c|}
\hline \multirow[b]{3}{*}{ Nutrient group } & \multicolumn{4}{|c|}{ SCI group (mean) } & \multicolumn{2}{|c|}{ RNI } \\
\hline & \multicolumn{2}{|c|}{ Men } & \multicolumn{2}{|c|}{ Women } & \multirow[b]{2}{*}{ Men } & \multirow[b]{2}{*}{ Women } \\
\hline & Baseline & $\overline{\text { Follow-up }}$ & Baseline & Follow-up & & \\
\hline Energy (MJ /d) & 7.65 & 6.13 & 5.58 & 5.1 & 10.6 & 8.1 \\
\hline Carbohydrate ( $\%$ food energy) & 44.8 & 46.2 & 45.3 & 47.7 & 50 & 50 \\
\hline Sugar ( $\%$ food energy) & 16.3 & 19.4 & 19.2 & 20.0 & 11 & 11 \\
\hline Protein ( $\%$ food energy) & 17.8 & 19.8 & 18.7 & 19.3 & & \\
\hline Fat ( $\%$ food energy) & 34.0 & 32.0 & 34.7 & 32.6 & 35 & 35 \\
\hline SFA & 9.4 & 10.7 & 8.8 & 10.1 & 11 & 11 \\
\hline MUFA & 9.2 & 10.2 & 9.7 & 12.1 & 13 & 13 \\
\hline PUFA & 6.0 & 5.9 & 5.6 & 6.3 & 6.5 & 6.5 \\
\hline Fibre & 13.6 & 14.7 & 10.2 & 10.2 & 18 & 18 \\
\hline Alcohol (g) & 9.8 & 3.3 & 2.6 & 2.1 & & \\
\hline
\end{tabular}

SCI: Spinal cord injury group; RNI: Reference Nutrient Intake ${ }^{3}$; SFA: Saturated fatty acid; MUFA: Mono-saturated fatty acid; PUFA: Poly-saturated fatty acid.

1. Spinal Injury Association (2009) http://www.spinal.co.uk/page/Some-basic-facts-about-SCI assessed 8th February 2010.

2. Gupta N, White K \& Sandford P (2006) Spinal Cord 44, 92-94.

3. Department of Health (1991) Dietary Reference Values of Food Energy and Nutrients for the United Kingdom. Report on Health and Social Subjects no. 41. London: H.M. Stationery Office.

4. Henry CJK (2005) Public Health Nutr 8, 1133-1152. 